\title{
El arbitraje institucional en Iberoamérica
}

\section{Roberto Omar Berizonce}

A Enrique Vescovi, maestro auténtico, luchador incansable, impulsor de la transformación del sistema judicial en Iberoamérica, en restimonio de admiración por su obra y su condición humana.

\section{Naturaleza y sentido «social» del arbitraje}

Desde sus más remotos orígenes el arbitraje aparece y se dibuja como método de solución de conflictos confiado a los particulares, a las personas comunes, anterior al Estado y a la intervención de los órganos especializados de la jurisdicción pública ${ }^{1}$. Las formas de solución privadas, la autocomposición, la mediación y el arbitraje en sus variadas modalidades formaban parte antiguamente, de hecho excluyente, de la jurisdicción, que históricamente antecediera a la legislación ${ }^{2}$. Cercanos estudios antropológicos confirmaron la gran importancia y desarrollo que en las sociedades primitivas han tenido la negociación, mediación, conciliación y el arbitramento ${ }^{3}$.

1 Gelsi Bidart A., "Significado de la promoción del arbitraje», en XII Jornadas Iberoamericanas de Derecho Procesal, Ed. Ministerio de Justicia, Madrid, España, 1990, v.I, pp. 689-690.

2 Calamandrei P., «El significado constitucional de las jurisdicciones de equidad", en Estudios sobre el proceso civil, E. B. A., Bs. As., 1945, trad. S. Sentis Melendo, pp. 64-68. La noción de jurisdicción, por ende, resulta independiente de su atribución por parte del Estado a unos órganos determinados. El órgano es así irrelevante a los efectos de determinar la función (Serra Domínguez M., Estudios de Derecho Procesal, Ariel, Barcelona, 1969, p. 580).

3 Así, los estudios que integraron The Florence Access-to-Justice Projet, en la 
En el devenir histórico, el arbitraje subsistió hasta nuestros días, al lado del proceso judicial, como instituto especial confiado a jueces privados -árbitros o amigables componedores- a los que por la voluntad de las partes se someten el conocimiento y decisión de sus diferencias; lo cual no obsta a su naturaleza jurisdiccional.

Claro que la jurisdicción arbitral y la función de los árbitros a través del dictado del laudo, suponen necesariamente la observancia inexcusable de las reglas esenciales del debido proceso constitucional: la decisión de un tercero imparcial e independiente a la que se arriba al cabo de un proceso que aunque simplificado y desacralizado, asegure la audiencia, contradicción e igualdad específica de las partes. Aún careciendo los árbitros de la coercio y la executio públicas, son de todos modos los jueces del caso particular sometido por los interesados para su composición; tienen autoridad porque ejercen la notio, la juditio y la vocatio, mas carecen de la potestad para imponer y ejecutar por sí sus laudos.

El amanecer del nuevo milenio encuentra a la tradicional figura del arbitraje pujando por alcanzar nuevos horizontes, en un despliegue que se abre en diferentes perspectivas, bajo el común denominador de su expansión para ocupar un lugar más destacado -cuantitativa pero también cualitativamente- en el "reparto" y atribución de espacios, en confrontación con la jurisdicción oficial. Remozamiento y aggiornamento del proceso arbitral antes confinado a los ordenamientos procesales y ahora a menudo resaltado en leyes especiales de arbitraje ${ }^{4}$, superadoras de los obstáculos que desde el diseño jurídico han impedido su consolidación; expansión y nuevos rumbos del arbitraje internacional $^{5}$, para servir útilmente en la nueva fase de armonización transnacional; gestación e impulso singular, en fin, a nuevas modalidades, como el denominado arbitraje institucional o administrado, del que nos hemos aquí de ocupar.

década de los '70, bajo la dirección de M. Cappelletti: Acces to Justice, M. Cappelletti editor general.

4 Berizonce R. O., "Recientes tendencias en la posición del juez», en El juez y la magistratura (tendencias en los albores del siglo XXI), R. O. Berizonce Relator General, Instituto Iberoamericano de Derecho Procesal, Rubinzal-Culzoni ed., Bs. As., 1999, pp. 46-48 y sus remisiones.

5 Morello A. M., Sosa G. L. y Berizonce R. O., Códigos Procesales..., Op. cit., v. IV-B, pp. 89-110;111-143. 


\section{El arbitraje como instrumento para el acceso a la justicia}

En los trazos gruesos de la reseñada evolución del arbitraje afloran con nitidez las aristas más típicas de un complejo fenómeno de nuestro tiempo: la actual «exposición» del arbitraje ${ }^{6}$, con reconocer causas múltiples y desde luego no lineales, no puede considerarse ajena, al menos, a cuatro tipos de motivaciones. En primer lugar, la eclosión en la sociedad finisecular de ciertas categorías de conflictos con muy particulares características -en general, los que se derivan de las denominadas relaciones de "coexistencialidad" y los "procesos sociales»-, diferendos para cuya composición determinados medios alternativos -y entre ellos, el arbitraje por sí sólo o articulado con la mediación o conciliaciónpresentan ventajas diferenciales en relación comparativa al proceso de cognición judicial. Segundo, e igualmente significante, la situación a menudo de impotencia del aparato oficial para brindar satisfacción adecuada -en tiempo y a costos razonables mediante decisiones intrínsecamente justas-, a los reclamos de los justiciables, que impulsa la "fuga» hacia tales medios alternativos imaginariamente recurridos como supuesta «tabla de salvación ${ }^{7}$. Tercero, no menos importante, la motivación profunda que supone la recurrencia a ciertas formas originarias de solución de diferendos -una suerte de "regreso a las fuentes»-, desentendidas de sacramentalidades y formalismos estériles, como forma simple de justicia confiada a jueces no profesionales («desjudicialización») y, por ello, quizá más humanizada. El ideal de «un proceso de rostro más humano» ${ }^{8}$ que cree verse realidad a través de esos medios que, sin ser sustitutivos, aspiran a equiparse al enjuiciamiento público. Cuarto (last but not least), en un contexto social crecientemente participativo política y socialmente, que a su vez conlleva por ello mismo a una mayor apetencia de justicia por parte de todos los ciudadanos, la nueva

6 Es la gráfica expresión que uriliza Artavia Barrantes S., La nueva ley de arbitraje de Costa Rica. Aciertos y desaciertos, comunicación al Congreso Internacional "Processi di integrazione e soluzione delle controversie: dal contenzioso fra gli stati alla tutela singoli.

7 Morello A. M., Estudios de Derecho Procesal. Nuevas demandas. Nuevas respuestas, LEP-Abeledo-Perrot, Bs. As., 1998, v. 1, pp. 587 y ss.; v. 2, pp. 849-852.

8 Cappelletti M. y Garth B., El acceso a la justicia, ed. Col. Abog. La Plata, 1983, trad. Amaral S., pp. 91 y ss. Vescovi E., op. cit., pp. 161-162. 
y remozada versión idealizada de las formas alternativas sólo puede convertirse en realidad en tanto se articule un sistema eficiente que, en paralelo a la justicia estatal, sea capaz de abastecer aquellas demandas. Se multiplica, entonces, la apuesta y el desafío, porque se espera (y debe darse) respuesta a una conflictividad exponencialmente creciente $y$, por añadidura, a menudo de alta complejidad técnica (procesos complejos) y procesal (procesos colectivos).

El arbitraje, entonces, se proyecta en diversas aunque convergentes direcciones: por un lado, atiende con un opus de calidad y mejor justicia intrínseca la parcela que tradicionalmente venía abasteciendo, la de los conflictos interempresarios, societarios, de seguros, transporte y mercantiles, en general. A perfeccionar el arbitraje en sus formas tradicionales tienden las remozadas preceptivas de los ordenamientos procesales y las nuevas leyes específicas, antes recordadas.

Sin embargo, otro diverso y mucho más extendido es el universo en el que, y para el que, se proyecta el arbitraje en la vertiente social. El tradicional mecanismo del arbitraje ad hoc, para la solución de los puntuales casos -naturalmente de singular utilidad y valía a esos fines-, resulta insuficiente desde el punto de vista organizacional cuando se pretende brindar respuesta a aquella creciente masa conflictiva que en estos tiempos busca refugiarse en las formas alternativas. Tampoco exhibe eficiencia un sistema de mediación "caso por caso", por razones que son comunes ${ }^{9}$.

Claro que el fenómeno del auge de los mecanismo "parajudiciales» que vienen a competir con la justicia pública, no es exclusivo de estos tiempos. Baste recordar las diversas jurisdicciones especiales y comisiones arbitrales de todo tipo que ya refería Calamandrei, que se multiplicaron en los años de la primera conflagración mundial, y más cercanamente los que aquí y allá se instalaron durante y después de la última gran guerra. El análisis histórico no deja de ser útil y sugiere reflexiones insoslayables; con la perspectiva del tiempo parece ingenua la conclusión principista del maestro florentino que veía en la proliferación de la jurisdicciones de equidad tan sólo un fenómeno de excepción y acotado por las circunstancias. Quizá la conclusión deba ser

9 Morello A. M., Estudios de Derecho Procesal..., Op. cit., v. 2, pp. 873-876: Conciliación y mediación. Más sombras que luces. 
diversa: aquellos órganos fueron, es cierto, producto de su tiempo, pero también lo es que en realidad son siempre frutos de un estado de necesidad; lo que entonces era necesidad transitoria, ahora se ha convertido en un estado de necesidad continuado y permanente, definitivamente afincado en nuestras circunstancias. De ahí que la recurrencia a los medios alternativos de solución de disputas se integra ahora, y está aposentado probablemente por mucho tiempo, en el arsenal de mecanismos de la justicia. Aserto que se sostiene tanto en el previsible incremento continuado de los reclamos, por la conciencia de un mayor y más efectivo acceso a la justicia, cuanto por las ventajas diferenciales que tales medios -y el arbitraje en particular, en lo que aquí interesaofrecen según las particulares clases de conflictos, sentado el acentuamiento de las tutelas diferenciadas.

Bien entendido, sin embargo, que en cualquiera de sus modalidades, el sometimiento al arbitraje privado no puede, en ninguna circunstancia, imponerse obligatoriamente a los particulares. Ello implicaría contrariar su esencia y razón de ser, que asienta en la libre voluntad negocial de las partes. La garantía constitucional de la defensa en juicio, es bien sabido, supone la oportunidad concreta para toda persona de hacer valer sus derechos en justicia, y por ende que se encuentren expeditas las vías útiles, ante un juez imparcial e independiente, que no es otro que el juez oficial. Sólo por la libre y espontánea voluntad de los interesados puede obviarse la vía judicial y, si se tratare además de conflictos sobre derechos disponibles no excluidos por la ley, es legítimo y operante el deliberado sometimiento a jueces particulares cuya competencia, de todos modos, solo se abre si son ambos contendientes de consumo quienes libremente escogen esa opción. Salvo los excepcionales supuestos en los que el desemboque arbitral viene, por la naturaleza singular (técnicas) de ciertas cuestiones conflictivas adosado al quehacer de jueces privados, sujeto de todos modos a la regla genérica del control judicial del laudo.

\section{El arbitraje institucional}

La organización institucional del arbitraje ofrece diversas peculiaridades que la diferencian del tradicional método del arbitraje ad hoc. Mientras en este último se confía individualmente a los árbitros espe- 
ciales convocados para dirimir el específico conflicto, quienes llevan a cabo su cometido vinculados tan solo por el lazo que les une a los propios requerientes y bajo su exclusiva responsabilidad; en cambio, en aquel, el enlace y la comisión se encarga a una entidad -pública estatal o no estatal o privada- que organiza, controla y responde por el singular servicio (por el buen servicio), dispensado por especialistas (árbitros) que se desempeñan por sí aunque bajo la gestión y responsabilidad de la institución administradora (arbitraje "administrado").

$\mathrm{Va}$ entendido, entonces, que tal tipo de arbitraje «administrado» supone un conjunto de actividades de organización, gerenciamiento, control y consecuente asunción de responsabilidad de la entidad por los «productos» (laudos) que se expidan. Dichos servicios pueden confiarse a organismos públicos -v. gr. cámaras de arbitraje o comisiones especiales para arbitrar en conflictos individuales del trabajo, locaciones, materia agraria, etc- ${ }^{10}$. Una modalidad de este tipo de entes se ha desarrollado recientemente para atender la tutela de los derechos de los consumidores (tribunales y juntas arbitrales de consumo); procuraduría de los consumidores y usuarios, entre otros).

Sin embargo, por la propia esencia del arbitraje que supone el emplazamiento voluntario de jueces privados, que por definición no han de ser funcionarios públicos ni integrar la nómina del personal de la administración, la modalidad por antonomasia de arbitraje «administrado» es el que se organiza y gestiona por entidades privadas, asociaciones, fundaciones, entes sectoriales (cámaras empresarias, organizaciones sindicales), incluyendo a ciertas entidades paraestatales públicas, aunque no estatales (colegios, órdenes o «barras» profesionales) o autónomas (institutos universitarios); y aún supranacionales (tribunales arbitrales del Mercosur).

La organización institucional del arbitraje presenta notorias ventajas comparativas en relación con el arbitraje ad hoc. Básicamente, porque la atención masiva de los reclamos se facilita por la organización de un íntegro sistema que se asemeja -debe asemejarse- al propio esquema jurisdiccional oficial. Una trama reglamentaria, siquiera mínima aun-

10 Así las comisiones especiales italianas ya aludidas por Calamandrei M., op. cit., pp. 71 y nota 24,87 y notas 53-56. En los países iberoamericanos son conocidos múltiples organismos administrativos de ese tipo. 
que de fuente legal, traza las pautas y principios que lo gobiernan: a) reglas de organización de los centros de arbitraje, entidades autorizadas, funciones, atribuciones; b) mecanismos de selección de los árbitros (concursos públicos); c) reglas de procedimiento arbitral (debido proceso, desacralización, informalismo) y supletoriedad; d) listas de árbitros y procedimiento de su confección, duración de los cargos, requisitos que deben reunir los aspirantes, reglas para la asignación a cada caso, causas de recusación y excusación; e) control de la actividad de los árbitros, régimen disciplinario; $\mathrm{f}$ ) costos del servicio, tarifas de honorarios y gastos; g) contralor público de los centros y régimen de responsabilidades derivadas del servicio (de la entidad y de los árbitros).

\section{Auge y expansión del arbitraje institucional}

El desarrollo "explosivo" del arbitraje institucional constituye un fenómeno en expansión, típico de la última década del siglo fenecido. En Brasil, la Ley de arbitraje de 1996, no obstante la inexistencia de una cultura favorable generó una multiplicación de los órganos arbitrales institucionales. No sólo se modernizaron los entonces existentes sino que se crearon entes nuevos, especialmente en los grandes centros urbanos, multisectoriales, con el apoyo de las asociaciones mercantiles, bajo la forma de centros de mediación y arbitraje. De hecho, se han amplificado las zonas de cobertura de tan novedosos sistemas, descentralizándose su operatoria; completándose y categorizándose el cuadro de los árbitros por sectores de actividad; se han adecuado las tablas de costos, tornándose más competitivas, en paralelo con un sostenido esfuerzo de divulgación y discusión del instituto ${ }^{11}$.

Un movimiento similar se ha producido en España, donde especialmente al amparo del Art. $10^{\circ}$ de la Ley $\mathrm{N}^{\circ} 36 / 1998$, han prolifera-

11 Barbosa Moreira J. C., "La nueva ley de arbitraje brasileña», en Rev. Urug. Der. Proc., FCU, Montevideo, 1997, No 4, pp. 475-491. Carmona C. A., arbitragem no Brasil no terceiro ano de vigencia da Ley 9307/96, comunicación al Coloquio Internacional "Processi di integrazione e soluzione delle controversie: dal contenzioso fra gli Stati alla tutela dei singoli. Europa e America Latina», Roma, 7-9 setiembre 1999, cit. Theodoro Junior $\mathrm{H}$., "A arbitragem como meio de solucao de controvérsias", en Genesis, Rev. Dir. Proc. Civ., Curitiba, 1999, No 14, pp. 103 y ss. 
do organismos arbitrales de todo tipo, cada uno esforzándose por «vender" su propia cláusula arbitral y compitiendo en un mercado jurídico atractivo, que sin embargo no deja de generar suspicacias ${ }^{12}$.

La misma tendencia se advierte, en general, en Colombia, principalmente a partir de la Ley general de arbitraje $\mathrm{N}^{\circ} 23$ de 1991, cuyo Art. $90^{\circ}$ diferencia el arbitraje institucional -que se realiza a través de los «centros de arbitramiento» organizados con sujeción a dicha preceptiva- del denominado «independiente», regulado por el Decreto $\mathrm{N}^{\circ}$ 2279 de 1989 y modificatorios. Diferenciación que reposa en la naturaleza del órgano que la administra, en tanto aquella se confía a asociaciones, fundaciones o agremiaciones y cámaras de comercio habilitadas para instituir centros de arbitraje, sometidos a la vigilancia del Ministerio de Justicia.

No ha sido ajena a esa línea la Ley de Arbitraje Comercial de Venezuela de 1998, que regula minuciosamente el «arbitraje institucional», previendo que una amplia gama de entidades no gubernamentales están autorizados para organizar sus propios centros de arbitrajes, dictando los respectivos reglamentos, bajo las condiciones que preceptivamente establece la ley relativas a sede permanente, infraestructura de apoyo, lista de árbitros y demás aspectos.

En Costa Rica, la Ley $N^{\circ} 7727$ de Resolución Alterna de Conflictos de 1998, superando la anterior legislación que omitía regular el arbitraje «administrado», impulsa ahora decididamente la creación de centros arbitrales con amplias facultades; entre otras, para resolver arbitrajes, aplicar su procedimiento a arbitrajes externos, conformar la lista oficial de árbitros. Los centros son autorizados por el Ministerio de Justicia, que controla su funcionamiento y está facultado para revocar la habilitación. La ley determina, sobre procedimiento -actos procesales mínimos, régimen de recursos, medidas cautelares, ejecución del laudo- ${ }^{13}$.

12 Ramos Mendez F., Enjuiciamiento Civil, J. M. Bosch ed., 1997, v. II, pp. 1118,1120 .

$13[\ldots]$ existentes, las organizaciones vinculadas a actividades económicas e industriales, las organizaciones cuyo objeto está relacionado con la promoción de la resolución alternativa de conflictos, las universidades e instituciones superiores académicas y las demás asociaciones y organizaciones que se crearen con posterioridad a la vigencia de esta ley que establezcan el arbitraje como uno de los medios de solución de las controversias, podrán organizar sus propios centros de arbitraje. Los centros 
El Código General del Proceso uruguayo (Ley No 15.982 de 1988) reconoce de pleno derecho los laudos dictados por las "cámaras de arbitraje», a los que se sometan las partes (Art. $472^{\circ}$, segundo apartado); ello permitió que se haya generalizado la posibilidad de remitirse a elegir alguno de los tribunales arbitrales permanentes que establecen las Cámaras de Arbitraje, que facilitan la selección de jueces particularmente especializados, con un costo apropiado ${ }^{14}$.

En México se ha destacado el papel relevante que cumple la Procuraduría Federal del Consumidor, creada en 1976 como organismo público descentralizado del gobierno federal y que tiene a su cargo la aplicación en el ámbito administrativo de la Ley federal de protección del consumidor (1992), con facultades para fungir como árbitro institucional. Misión similar se adjudica para intervenir en los conflictos entre los usuarios de servicios financieros y las entidades financieras, a la Comisión Nacional de Protección y defensa de los derechos usuarios de servicios financieros ${ }^{15}$.

creados antes de la vigencia de esta ley, podrán continuar funcionando en los términos aquí establecidos y deberán ajustar sus reglamentos a los requerimientos de la misma. Artículo $12^{\circ}$. En el arbitraje institucional todo lo concerniente al procedimiento arbitral, incluyendo las notificaciones, la constitución del tribunal, la recusación y el reemplazo de árbitros y la tramitación del proceso, se regirá de conformidad con lo dispuesto en el reglamento de arbitraje del centro de arbitraje al cual las partes se hayan sometido. Artículo $13^{\circ}$. Todo centro de arbitraje ubicado en Venezuela tendrá su propio reglamento, el cual deberá contener: a) Procedimiento para la designación del director del Centro, sus funciones y facultades; b) Reglas del procedimiento arbitral; c) Procedimiento de elaboración de la lista de árbitros, la cual será revisada y renovada, por lo menos cada año; los requisitos que deben reunir los árbitros; las causas de exclusión de la lista; los trámites de inscripción y el procedimiento para su designación; d) Tarifas de honorarios para árbitros y tarifas de gastos administrativos, las cuales serán revisadas y renovadas cada año; e) Normas administrativas aplicables al centro; y f) Cualquier otra norma necesaria para el funcionamiento del centro. Artículo $14^{\circ}$.

14 Gelsi Bidart A., Significado de la promoción del arbitraje, op. cit., pp. 694695. Asimismo, Greif J., Informe nacional uruguayo en El juez y la magistratura..., op. cit., p. 497. La Ley No 16.995 de 1998 impuso la asistencia letrada obligatoria en la instancia arbitral y en la mediación (Calvo Carballo M. L., "Jueces conciliadores...» en Estudios de Derecho Procesal en homenaje a Adolfo Gelsi Bidart, Inst. Urug. Der. Proc., FCU, Montevideo, 1999, pp. 591 y ss).

15 Ovalle Favela J., op. cit., pp. 347-440. 
En otros países, como Argentina, están proliferando los organismos que ofrecen arbitraje "administrado", aún sin una preceptiva legal que los regule, lo cual naturalmente constituye un obstáculo severo. De todos modos, dejando de lado la instalación en curso de tribunales administrativos para el arbitraje en las relaciones de consumo ${ }^{16}$, ocupan un lugar destacado los tribunales arbitrales institucionalizados que organizan las cámaras empresarias ${ }^{17}$. Es tradicional y con extensa y reconocida actuación el Tribunal Arbitral de la Bolsa de Comercio de Buenos Aires ${ }^{18}$, experiencia emulada por otras entidades similares ${ }^{19}$.

16 Resulta novedoso el ya aludido sistema de arbitraje de consumo instituido en la Provincia de Buenos Aires -aún no ha sido puesto en funcionamiento-, por el cual se crean bajo dependencia ministerial los tribunales arbitrales de consumo que han de funcionar en el ámbito de los colegios de abogados departamentales (18), conformados por tres árbitros, uno designado entre los representantes de las asociaciones de consumidores, otro por los representantes de las asociaciones empresariales, y el tercero que lo presidirá como árbitro institucional, un abogado especializado, designado por la autoridad de aplicación de entre los inscriptos en un registro especial (arts. $1^{\circ}$, $7^{\circ}, 8^{\circ}$, dec. 1667/99). Las decisiones tienen carácter vinculante produciendo “idénticos efectos a la cosa juzgada para ambas partesm; sin perjuicio de ello, los laudos dictados por los tribunales arbitrales pueden ser recurridos ante una Junta Arbitral de Consumo de composición igualmente proporcional (arts. $4^{\circ}$ a $6^{\circ}$ ). Cuando el proveedor hubiere realizado oferta pública de sometimiento al sistema de arbitraje respecto de futuros conflictos con consumidores o usuarios, el compromiso quedará formalizado con la solicitud de arbitraje que presente el reclamante (Art. 170).

17 En lo pertinente y esencial los reglamentos de los distintos tribunales arbitrales se ajustan a las pautas de la ley modelo de arbitraje comercial internacional (UNCITRAL) de 1985. Conf.: Morello A. M., Sosa G. L. y Berizonce R. O., Códigos Procesales..., op. cit., v. IV-B.

18 Reglamento aprobado en 1971, con reformas de 1972, 1979 y 1993 . Puede verse su texto en Morello A. M., Sosa G. L. y Berizonce R. O., op. cit. en nota anterior, pp. 83-88. El tribunal actúa como árbitro de derecho o amigable componedor, conforme a la modalidad escogida por las partes; si nada se hubiere estipulado, debe proceder y decidir como amigable componedor (Art. No 2, reglamento cit.).

19 Entre otros, en 1989 se creó el Tribunal de Arbitraje Permanente de la Bolsa de Comercio de Bahía Blanca, que se desempeña como árbitro de derecho o amigable componedor. Conforme a su reglamento, se instituye un proceso sumario con inmediación del tribunal en dos audiencias, una preliminar y otra de vista de la causa. También funciona con beneplácito de los sectores involucrados el Tribunal de la Bolsa de Cereales de Buenos Aires (Caivano R. y Goyeneche A. T., El arbitraje en el comercio de granos, J. A., Bs. As., 1985-II, pp. 807 y ss.). 
Importa atender la conformación, a partir de los años noventa, de órganos de arbitraje permanente en el seno de los colegios profesionales de abogados ${ }^{20}$, notarios y de ciencias económicas. Resulta particularmente interesante la labor en este terreno de los colegios de abogados de la Provincia de Buenos Aires ${ }^{21}$-entidades de derecho público creadas, por ley, pero que aunque sujetas a contralor público no integran la administración estatal-, que han acordado un reglamento arbitral uniforme para ser adoptado por las dieciocho entidades departamentales que componen el organismo provincial ${ }^{22}$. En la misma línea la Federación Argentina de Colegios de Abogados (FACA) -persona jurídica privada- sancionó en 1993 su reglamento de conciliación y arbitraje. Asimismo, el Consejo de Colegio y Ordenes de Abogados del Mercosur (COADEM) instituyó el Tribunal Permanente de Conciliación y Arbitraje Institucional ${ }^{23}$.

Iberoamérica, en definitiva, asiste en la última década al remozamiento del arbitraje tradicional, a partir de la sanción de leyes especiales o la actualización de los ordenamientos procesales para dar cabida, entre otras modalidades, al arbitraje institucional ${ }^{24}$, y aún al cobijo de

$20 \mathrm{El} \mathrm{H}$. Colegio de Abogados de Barcelona instituyó un tribunal arbitral modelo que ha servido de inspiración a emprendimientos similares. Las leyes profesionales de la abogacía argentina, sancionadas a partir de fines de los años “40, atribuyen a los colegios la facultad de aceptar arbitrajes; así, entre otras, la Ley No 5177 (1948) de la Provincia de Buenos Aires. Morello A. M. y Berizonce R. O., Las entidades profesionales y los desafíos del presente, J. A., Bs. As., 1985-II, pp. 665 y ss. Berizonce R. O., Efectivo acceso a la justicia, LEP, La Plata, 1987, pp. 94-95; 194-195; id., Derecho Procesal Civil actual, op. cit., pp. 607-608. Caivano R., El arbitraje como modelo alternativo..., La Ley, Bs. As., 1989-C, p. 1125.

21 Se ha destacado la proficua labor del tribunal arbitral del Colegio de Abogados de Mar del Plata, especialmente por el alto índice de acuerdos amigables logrados. Conf.: Hooft E. R., Games L. M. y Gulminelli R. L., Tribunal Arbitral del Colegio de Abogados de Mar del Plata, La Ley, Bs. As., 1999-C, pp. 1027 y ss.

22 Reglamento de Conciliación y Arbitraje Institucional aprobado el 24-4-1998. Publicado por Col. Abog. Prov. Bs. As., 1998.

23 Reglamento aprobado en reunión plenaria de C.O.A.D.E.M. del 31-03-1996. Publicado en La abogacía organizada en el proceso de integración del Mercosur, ed. Col. Abog. San Isidro, Argentina, agosto 1998, año II, No 5, pp. 16 y ss.

24 Berizonce R. O., "Recientes tendencias en la posición del juez» en El juez y la magistratura..., R. O. Berizonce Relator General, op. cit., pp. 46-48. También en Chile, donde existe una larga y exitosa tradición de justicia arbitral, la falta de sanción 
las leyes comunes que han posibilitado la instalación de centros de arbitraje «administrado».

\section{Desafíos y perspectivas}

El reflorecimiento de la vieja institución arbitral domina, junto con otros medios alternativos para dirimir los conflictos, una parte no desdeñable del escenario del sistema de justicia, en un tiempo histórico de profundas mutaciones políticas, económicas y sociales, en el que los juristas porfían denodadamente por articular en concreto respuestas adecuadas a las exigencias de la gente.

Aún partiendo de la premisa pacíficamente aceptada que el arbitraje aplicado a negocios privados presenta ciertas ventajas comparativas en relación al proceso jurisdiccional, en particular para ciertas categorías diferenciadas de controversias -sea por la especialización del órgano, cuanto por la mayor flexibilidad e informalidad de los procedimientos y la consecuente celeridad en la adopción de los laudos-, es lo cierto que la aún corta experiencia de los años ' 90 , insuficiente claro para evaluaciones definitivas, ha puesto de resalto más dudas que certezas, más sombras quizás que luces.

El arbitraje «administrado» o institucional comienza a dar sus primeros, y siempre encarpados, pasos en un medio -común, en general, en todos los países del área iberoamericana- poco proclive a aceptar la declinación de la competencia judicial y su transferencia a jueces particulares -aunque tal transvasamiento no sea total, por la subsistencia de cierto control judicial que no cabe suprimir-. Razones diversas y complejas siguen resistiendo el avance de las soluciones arbitrales, en intensidad muy superior incluso a cierto desdén que se advierte respecto, v. gr., de la mediación-conciliación.

No están en cuestión las bondades técnicas que se adjudican al arbitraje, sino su operancia y virtualidad práctica a partir de su efectiva experiencia ${ }^{25}$. Si bien son notorios los avances en punto a la difusión

de un ordenamiento especial y actualizado no ha sido obstáculo para su desarrollo pujante (Tavolari Oliveros, informe nacional chileno, en op. cit., pp. 285-587).

25 Berizonce R. O., Derecho Procesal Civil actual, op. cit., pp. 582 y ss. Se ha sostenido que en general el público considera ineficiente la justicia privada: Arguedas 
de estas instituciones, de todos modos no han penetrado aún en la estimativa colectiva. Entre los propios abogados, operadores principales en el esquema, subsisten resquemores y desconfianzas alentadas a veces, es cierto, por sus propios intereses; pero si no están ellos convencidos difícilmente sus defendidos declinen la jurisdicción de los jueces oficiales, que aún en un marco de ineficiencia del servicio judicial ofrecen todavía garantías objetivas mínimas no desdeñables ${ }^{26}$. Porque no obstante sus conocidas rémoras se considera que puede conjugar mejor y más adecuadamente los principios de igualdad de las partes ${ }^{27}$ y la razonabilidad comparativa de los costos, verdadero "talón de Aquiles" del arbitraje.

El modelo superador debe provenir de la articulación y puesta en práctica de un eficiente sistema de arbitraje institucional, organizado de modo que pueda ofrecer ventajas manifiestas en comparación con el sistema judicial, en confiabilidad, en celeridad procesal y sobre todo en ahorro de costos y en la calidad de las decisiones («llave en mano", es decir al momento de la efectiva satisfacción de lo pretendido). De lo contrario, seguramente los litigantes seguirán "prefiriendo" el proceso jurisdiccional común.

La mejor calidad no se mide tan sólo en términos técnicos -por la mayor especialización- sino que está referida también a una cualidad

Salazar O., informe nacional costarricense en El juez y la magistratura..., op. cit., p. 231. Sobre la desconfianza y temores de los abogados: Morello A. M., Los abogados. Desafíos de los años 90, LEP, La Plata, 1993, pp. 76-77.

26 Entre las conclusiones del relatorio general sobre «recientes tendencias en la posición del juez», en el XI Congreso Internacional de Derecho Procesal (Viena, agosto de 1999), quedó de resalto la paradoja de la creciente «jurisdiccionalización», por la mayor recurrencia de los ciudadanos ante el Poder Judicial, no obstante la ineficiencia comprobada del sistema jurisdiccional y aún, el desprestigio de la magistratura, fenómeno particularmente notable en los países latinoamericanos. Berizonce R. O., «Recientes tendencias en la posición del juez», op. cit., pp. 57-58.

27 Se ha sostenido en tal sentido que en realidad más que el arbitraje, es menester ensanchar los mecanismos sociales de solución de conflictos, como la conciliación en equidad a través de los jueces de paz (Parra Quijano J., informe nacional colombiano, en op. cit., pp. 222-223). En sentido similar, hay que estimular la creación de centros de arbitraje para darle satisfacción al 88 por ciento de la población que, por falta de recursos, no accede al sistema de justicia formal, para lo cual debería considerarse obviamente los costos del sistema y los honorarios de los árbitros (Quintero Tirado M. informe nacional venezolano en op. cit. p. 574). 
del órgano y del "producto" (laudo) cual es, en relación a ciertas controversias, el contar con una decisión justa y equitativa (fair and equitable $)^{28}$. De ahí que el arbitraje institucional debe ser de derecho $y$, también y preferentemente de amigables componedores (árbitros de equidad) ${ }^{29}$. Más aún, este último ofrece inmejorables posibilidades para abastecer cierto tipo de conflictividad simple, porque no entra a competir con los jueces oficiales y viene a superar, por la informalidad de los procedimientos, el sacramentalismo tan criticable de los procesos jurisdiccionales. En correspondencia, no se requiere de patrocinio letrado obligatorio.

La reducción de los costos es no menos esencial. Si el arbitraje resultara tanto o más oneroso que la justicia pública, se confirmaría la creencia común que le adjudica un carácter elitista; sería inviable a los fines de erigirse en un «equivalente jurisdiccional». La menor onerosidad, al igual que cuando se trata del proceso común, ha de pasar necesariamente por el abaratamiento de los costos de los abogados, periciales y, naturalmente, el agregado de los emolumentos de los árbitros y las tasas arbitrales no deberá incidir en la sumatoria general. En definitiva, tal sumatoria debe expresar guarismos finales menores -mejor aún, considerablemente inferiores- a los que eroga la justicia oficial.

El montaje del sistema institucional -con lo que deben lidiar las entidades que aspiran a prestarlo- implica la selección de los árbitros mediante concursos públicos, la organización y gestión burocrática de los centros de arbitraje, incluyendo el asesoramiento gratuito para los carentes de recursos, el control de la actividad de los árbitros y el ejercicio del poder disciplinario, en fin, el dictado de los respectivos reglamentos. Habrá de cuidarse de no generar una nueva burocracia paralela a la judicial, para poder instalar una organización eficiente y dispuesta para atender la conflictividad que, de algún modo graciosamente, esté dispuesta a recurrir a los jueces particulares.

28 Cappelletti M. y Garth B., op. cit., p. 124. Sobre las jurisdicciones de equidad, Calamandrei P., op. cit., pp. 64 y ss.

29 Los amigables arbitradores o componedores actúan sin subordinación a formas determinadas, pero sujetos a los principios básicos del debido proceso y la igualdad de las partes. Si bien resuelven "según su saber y entender», «a verdad sabida y buena fe guardada». 
Para ahuyentar el temido estigma de una "semijusticia» (Bentham) o "justicia de segunda", sustituto caritativo y caricaturezco de la jurisdicción oficial, que alienta en el inconsciente colectivo cada vez que se opera un desplazamiento del régimen natural, en menester optimizar la prestación arbitral, que debe trepar hasta los más altos registros de confiabilidad, calidad y seguridad jurídica. Contar con -y antes, capacitar árbitros altamente dotados, especializados y confiables, con vocación señalada, porque no se asentará el arbitraje institucional si se muestra incapaz de emular y aún superar a los propios jueces oficiales, con los que han de competir, de uno u otro modo. En ello radica el arduo desafío que plantea el arbitraje en la dimensión institucional. Sólo cabe ahora la apuesta, que el tiempo dirá si se alumbra una ilusión o se desvanece otra esperanza. 